\title{
First case report of enzootic nasal adenocarcinoma in "Ouled Djellal" ewe in Algeria
}

\author{
Nassim Sid ${ }^{1, *}$, Nour El Houda Belalmi ${ }^{2}$, Louiza Benhamza ${ }^{1}$, Soraya Ouhida ${ }^{3}$, Mohammed Ezine Zebiri ${ }^{4}$, \\ Ahmet Aydoğan ${ }^{5}$ and Caroline Leroux ${ }^{6}$ \\ ${ }^{I}$ GSPA research Laboratory (Management of Animal Health and Productions), Institute of Veterinary Sciences, \\ Frères Mentouri University, BP 325, route Ain El Bey, Constantine, 25100, Algeria \\ ${ }^{2}$ Institute of Veterinary Science, Elkhroub, Frères Mentouri University, BP 325, route Ain El Bey, Constantine, \\ 25100, Algeria \\ ${ }^{3}$ University Hospital Center Saadna Mohamed Abdennour, Street Ibn Sina, Setif, 1900, Algeria \\ ${ }^{4}$ Directorate of Agricultural Services, Bord Bou Arreridj, 34000, Algeria \\ ${ }^{5}$ Department of Pathology, Faculty of Ceyhan Veterinary Medicine, Çukurova University, Adana, Turkey \\ ${ }^{6}$ IVPC UMR754, INRA, Univ Lyon, Université Claude Bernard Lyon 1, EPHE, 50 avenue Tony Garnier 69007, \\ Lyon, France
}

\begin{abstract}
We report clinical and pathological features of enzootic nasal adenocarcinoma (ENA) in one sheep in Algeria. A oneyear-old Ouled Djellal sheep from a large herd ( 1240 animals), located in Bordj Bou Arreridj, Algeria, was clinically diagnosed by the presence of persistent seromucous nasal discharge, head shaking, muzzle licking, dyspnoea, exophthalmia and frontal protrusion. The sheep was euthanized, and the necropsy was performed. Gross examination showed soft touch, pinkish-white tumour masses in the nasal cavities with distortion of the turbinates and of the medium septum. According to clinical and pathological findings, the tumour has been defined as a low grade mixed nasal adenocarcinoma, with the presence of tubular and papillary structures. This is, to our knowledge, the first report of ENA in Algeria known to be associated with enzootic nasal tumour virus (ENTV) infection. However, such association requires confirmation by direct and/or indirect viral investigation.
\end{abstract}

Keywords: Algeria, Enzootic nasal adenocarcinoma, Ouled Djella sheep.

\section{Introduction}

Enzootic nasal adenocarcinoma (ENA) is a chronic and contagious tumour in sheep and goats, characterised by tumoral proliferation of secretory epithelial cells in the nasal cavity (De las Heras et al., 2003; Svara et al., 2006; Ozmen et al., 2010). This animal cancer is induced by enzootic nasal tumour virus (ENTV), one of the retrovirus inducing diseases in small ruminants (Leroux and Mornex, 2008).

Retroviruses are RNA viruses, widely distributed in most vertebrate and in many non-vertebrate species; among them, small ruminant lenti viruses (SRLV), jaagsiekte sheep retro virus (JSRV) and ENTV infect and induce diseases in small ruminants. ENA has been first described in Germany in 1939 and subsequently reported in all major sheep and goat farming areas (De las Heras et al., 2003).

This tumour is naturally occurring worldwide and has been reported in many countries and more recently in Turkey (Ozmen and Serpin, 2016). ENTV is highly related to JSRV, another oncogenic betaretrovirus responsible for pulmonary lung adenocarcinoma in small ruminants (Cousens et al., 1999; Monot et al.,
2015). Coinfection with these two oncogenic viruses has been reported in sheep (Ortin et al., 2004).

Based on their complete nucleotide sequences, ENTVs isolated from goat and sheep are distinct viruses with ENTV-1 and ENTV-2 respectively present in sheep and goats (Cousens et al., 1999; Ortín et al., 2003). These oncogenic retroviruses transform epithelial cells though their envelope (Monot et al., 2015).

Clinically, the affected animals show persistent nasal discharge, dyspnoea, stertorous breathing, and productive cough; open mouthed breathing, exophthalmos, and facial deformity are often seen (De las Heras et al., 2003). Gradually, the animals lose weight with time and finally die.

The diagnosis of enzootic nasal tumour (ENT) may be mistaken for other diseases of small ruminant such as bacterial and fungal infections, dust allergy or oestrosis, however, the latter one is the main disease for which differential diagnosis is sometimes difficult (De las Heras et al., 2003).

Nevertheless, exophthalmia and cranial deformation should be evocative of nasal tumour for veterinarians during differential diagnosis. The suspicion of nasal 
tumour can be easily confirmed by pathological examination of sagittal section of the head and of the tumour (Ozmen and Serpin, 2016). This report presents the first case of nasal tumour in a Ouled Djellal sheep from Algeria.

\section{Case Details}

In February 2014, a one-year-old ewe of "Ouled Djellal" breed was presented with persistent seromucous nasal discharge, head shaking, muzzle licking, respiratory distress, exophthalmia and frontal protrusion with major facial deformation (Fig. 1A). The animal came from a large herd ( 1240 animals) of the "Abbasi Larbi" pilot farm located in Bordj Bou Arreridj in the North part of Algeria. No other animals presented with the same clinical signs, but the owner reported that one sheep died over the last two years with similar clinical symptoms, in absence of necropsy and pathological examination.

The affected sheep was euthanized and complete necropsy was performed. After longitudinal cut of the head along the midline, bilateral, friable tumour masses were found in the caudal part of the nasal cavity closely attached to the mucous membrane of the ethmoid turbinates (Fig. 1B). The sizes of the tumours were respectively $6.5 \times 6 \times 4.3 \mathrm{~cm}$ and $3.5 \times 3 \times 1.7 \mathrm{~cm}$ in the right and left sides of the nasal cavities. Masses, with lobular appearance, were soft touch, pinkish-white in colour and they completely obstructed the nasal cavities; they were covered by clear mucous exudate. They were associated with inflammation, necrosis and distortion of turbinates and of the medial septum. The masses invaded in the frontal sinuses and compressed retro-ocular structures. Softening, atrophy and perforation were observed in the right side of the frontal, lacrimal and ethmoidal bones (Fig. 1C). No metastases were detected in regional lymph nodes, lung, brain, liver, kidney or other organs and tissues. Tumours were collected, immediately fixed in $10 \%$ neutral buffered formalin, embedded in paraffin, cut into five $\mu \mathrm{m}$ thick sections, stained with haematoxylineosin (HE) and examined microscopically. The skull was prepared for detailed examination of bone lesions. Microscopical examinations showed neoplastic cells arranged in tubular and papillary structures (Fig. 2A). Neoplastic cells were mostly cuboidal and occasionally columnar, with distinct cell borders and a moderate amount of eosinophilic cytoplasm. The nuclei were uniform, round to oval, with clumped chromatin pattern and several small nucleoli, located centrally or in the basal parts of the cells. Mitotic figures were rare (Fig. 2B). The stromal fibrous connective tissue was infiltrated by numerous lymphocytes, plasma cells and macrophages and varied from scattered to more abundant in some areas (Fig. 2C).

\section{Discussion}

ENA in small ruminants may be an economically important contagious neoplasm of the nasal mucosal glands with a prevalence of up to $10 \%$ in some areas (De las Heras et al., 2003). This animal cancer has been reported in many countries, among them African countries (Charray et al., 1985; Kane et al., 2004; Ajayi et al., 2013). Based on the literature, our study is the first report of ENT in North Africa in Algeria in a sheep of "Ouled Djellal" breed.

The clinical signs evolve during the tumour progression. Persistent sero-mucous nasal discharge and signs attributable to upper respiratory obstruction including nostril flaring, dyspnoea and mouth breathing are frequently reported (De las Heras et al., 2003). Exophthalmia, skull deformations, facial asymmetry, as reported in our case, and weight loss may also be observed (McKinnon et al., 1982; De las Heras et al., 2003; Svara et al., 2006).

The clinical and pathological findings in the Ouled Djellal sheep were characteristic and like those described previously (De las Heras et al., 2003), with bilateral whitish to pinkish tumours in the ethmoid turbinate. The structure of the ethmoid, lacrimal and frontal bones was gradually lost during tumour extension. We evidenced bone perforation, probably attributable to tumour compression on the bone structures (De las Heras et al., 2003).

In the present case, we observed a mixed adenocarcinoma, with tubular and papillary lesions. ENT should be considered as a low-grade adenocarcinoma with papillary lesions as the most common subtype of histological lesions (Aydogan and Ozmen, 2016); mucinous, tubular, and acinar patterns are also present in the tumoral tissues (Wilson, 2016). The diagnosis of ENA is usually based on gross and histologic findings (Caswell and Williams, 2007; Sharp and De las Heras, 2007).

Better identify the disease is of relevance for the control of these virally-induced tumours. Sheep and goats presenting with nasal tumours often produce mucous exudates through the nostrils. Then as for JSRV (Monot et al., 2015), ENTV is probably spread horizontally, most likely by the respiratory route. ENT has been successfully reproduced by experimental nebulization with cell-free tumour homogenates (Walsh et al., 2013) and concentrated nasal discharge of naturally infected goats (De las Heras et al., 1995).

Other routes of transmission should not be excluded such as milk, colostrum or intra-utero or perinatal infection, like it has been reported for JSRV (Caporale et al., 2005; Grego et al., 2008). Cases of enzootic nasal cancer can occur in a disease-free flock following the introduction of infected animals. 

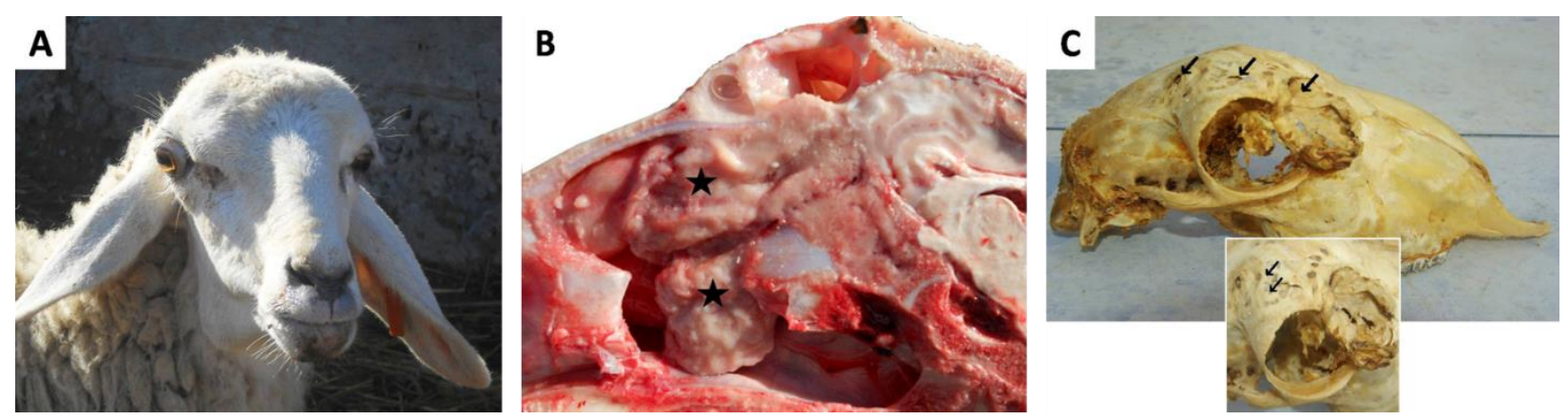

Fig. 1. Clinical and gross examination of one-year-old ewe of "Ouled Djellal" breed with nasal tumour. (A): Nasal discharge, exophthalmia, deformation of the frontal bone and facial asymmetry. (B): Sagittal section of the head with tumoral masses ( $\star$ ). (C): Softening and perforation of the frontal, lacrimal and ethmoidal bones $(\swarrow)$.
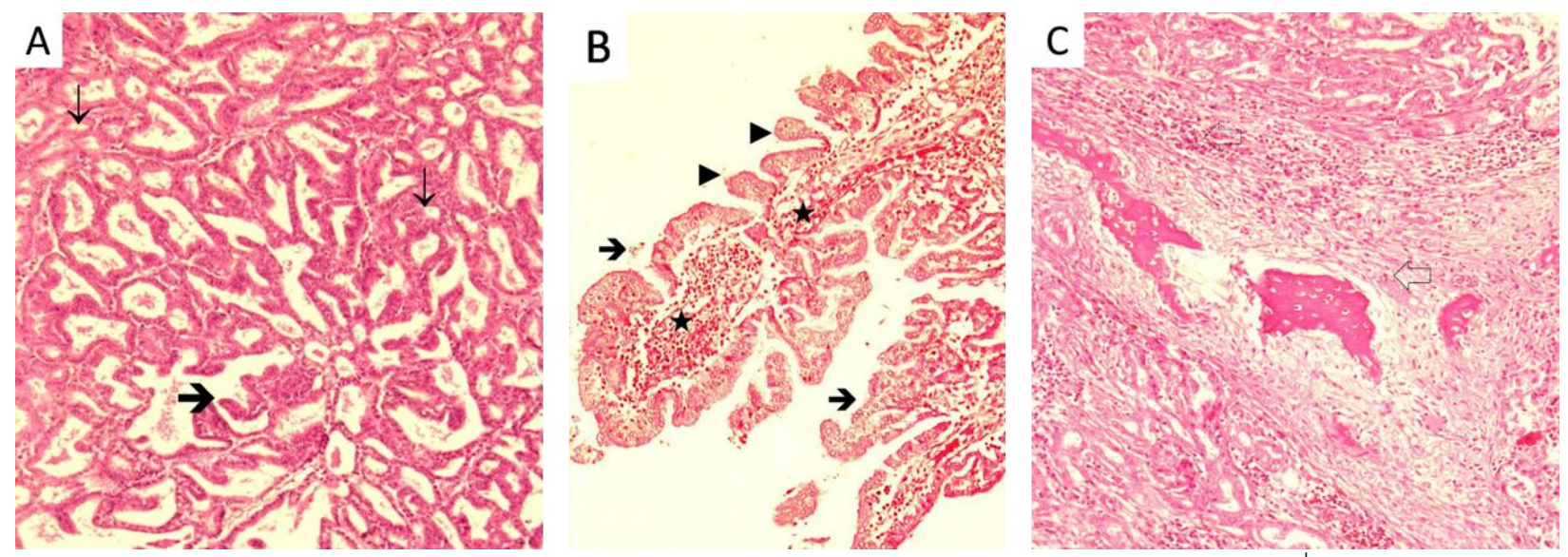

Fig. 2. Pathological presentation of the nasal adenocarcinoma (HE, magnification X100).(A): Tubular ( $\downarrow$ ) and papillary ( $\rightarrow$ ) patterns of nasal adenocarcinoma. HE x 100. (B): Papillary $(\rightarrow)$ projections. Note the epithelial layer composed mainly of nonciliated cells $(\rightarrow)$ with thin oval nuclei and mononuclear cells $(\star)$ infiltrating into the stroma. HEx100. (C): Stroma infiltration of lymphocytes and plasma cell (ઐ) (H\&E x100).

In this study, we cannot define the route of contamination or of virus introduction. At least one sheep presented with the same clinical signs and other animals may have developed tumours or misinterpreted subclinical signs. ENTV infection and the induced cancer may be present as well as asymptomatic infected animals. To note that the farmer reported the purchase of only breeding rams in his herd of unknown status regarding the ENTV or disease status. ENA is a progressive and contagious tumour and generally considered as sporadic. But in some circumstances, enzooties may be observed and in these cases may be responsible for economic losses. For that reasons, veterinarians should consider this disease in face of cranial deformation and/or exophthalmia associated with nasal discharge. In absence of treatment, culling affected animals is the only way to control this disease and limit virus spreading among small ruminants. Incidence and prevalence of ENA and ENTV infection in sheep in Algeria remain to be determined and might be underestimated. Our observation prompt us to be more vigilant to limit the spread of these deadly virusinduced cancers into small ruminant herds and to develop virus detection.

\section{Conflict of interest}

The authors declare that there is no conflict of interests.

\section{References}

Ajayi, O.L., Oyewusi, I.K., Olaniyi, M.O., Oyekunle, M.A., Jagun, A.T., Omotainse, S.O. and Biobaku, K. 2013. Enzootic nasal adenocarcinoma: Cytological and clinicopathological observations in a West African Dwarf goat. Bull. Anim. Health Prod. Afr. 61, 331-336.

Aydogan, A. and Ozmen, O. 2016. Expression of nectin-4 as a potential biomarker in enzootic nasal adenocarcinoma of goats. Acta Vet. Hung. 64(1), 71-77.

Caporale, M., Centorame, P., Giovannini, A., Sacchini, F., Di Ventura, M., De las Heras, M. and Palmarini, M. 2005. Infection of lung epithelial cells and induction of pulmonary adenocarcinoma is not the most common outcome of naturally occurring JSRV infection during the commercial lifespan of sheep. Virology 338, 144-153.

Caswell, J.L. and Williams, K.J. 2007. Respiratory system. in: M. Grant Maxie (Ed.) Jubb, Kennedy, and Palmer's Pathology of Domestic 
Animals. Edinburgh: Elsevier Saunders. $5^{\text {th }}$ ed. pp: 620-621.

Charray, J., Aman, N. and Tanoh, K.G. 1985. Note sur une enzootie d'adénocarcinome de la muqueuse pituitaire chez des brebis Djalonké. Rev. Elev. Méd. Vét. Pays. Trop. 38, 406-410.

Cousens, C., Minguijon, E., Dalziel, R.G., Ortin, A., Garcia, M., Park, J., Gonzalez, L., Sharp, J.M. and de las Heras, M. 1999. Complete sequence of enzootic nasal tumor virus, a retrovirus associated with transmissible intranasal tumors of sheep. J. Virol. 73, 3986-3993.

De las Heras, M., Garcia de Jalon, J.A., Minguijon, E., Gray, E.W., Dewar, P. and Sharp, J.M. 1995. Experimental transmission of enzootic intranasal tumors of goats. Vet. Pathol. 32, 19-23.

De las Heras, M., Ortín, A., Cousens, C., Minguijón, E. and Sharp, J.M. 2003. Enzootic nasal adenocarcinoma of sheep and goats. Curr. Top. Microbiol. Immunol. 275, 201-223.

Grego, E., De Meneghi, D., Alvarez, V., Benito, A.A., Minguijón, E., Ortín, A., Mattoni, M., Moreno, B., Pérez de Villarreal, M., Alberti, A., Capucchio, M.T., Caporale, M., Juste, R., Rosati, S. and De las Heras, M. 2008. Colostrum and milk can transmit jaagsiekte retrovirus to lambs. Vet. Microbiol. 130, 247-257.

Kane, Y., Rosati, S., Diop, O.M., Profiti, M., Niang, I., Kadja, M., Kaboret, Y.Y., Alogninouwa, T. and Lena, P. 2004. Enzootic nasal tumour virus demonstrated in sheep in Senegal by direct detection of provirus from tumour DNA. Vet. Rec. $155,526-528$.

Leroux, C. and Mornex, J.F. 2008. Retroviral infections in sheep and the associated diseases. Small Rumin. Res. 76, 68-76.

McKinnon, A.O., Thorsen, J., Hayes, M.A. and Misener, C.R. 1982. Enzootic nasal adenocarcinoma of sheep in Canada. Can. Vet. J. 23, 88-94.
Monot, M., Archer, F., Gomes, M., Mornex, J.F. and Leroux, C. 2015. Advances in the study of transmissible respiratory tumours in small ruminants. Vet. Microbiol. 181, 170-177.

Ortín, A., Cousens, C., Minguijón, E., Pascual, Z., Villarreal, M.P., Sharp, J.M. and Heras, M.e.L. 2003. Characterization of enzootic nasal tumour virus of goats: complete sequence and tissue distribution. J. Gen. Virol. 84, 2245-2252.

Ortin, A., Perez de Villarreal, M., Minguijon, E., Cousens, C., Sharp, J.M. and De las Heras, M. 2004. Coexistence of enzootic nasal adenocarcinoma and jaagsiekte retrovirus infection in sheep. J. Comp. Pathol. 131, 253-258.

Ozmen, O., Sahinduran, S., Halıgur, M. and Demir, N. 2010. Clinical, Pathological, Immunohistochemical and Ultrastructural Observations on Enzootic Nasal Adenocarcinoma in Five Goats. Afkas Univ. Vet. Fak. Derg. 16, 633-639.

Ozmen, O. and Serpin, N. 2016. First case of enzootic nasal adenocarcinoma (ENA) in a Sheep in Turkey. MAE. Vet. Fak. Derg. 1, 87-90.

Sharp, J.M. and De las Heras, M. 2007. Contagious respiratory tumours. In: Aitken ID, Diseases of sheep. $4^{\text {th }}$ ed. Oxford, Blackwell Science, pp: 211217.

Svara, T., Gombac, M., Vrecl, M., Juntes, P., Kostanjsek, R., Pogacnik, A. and Pogacnik, M. 2006. Enzootic nasal adenocarcinoma of sheep in Slovenia. J. Vet. Med. A. Physiol. Pathol. Clin. Med. 53, 26-29.

Walsh, S.R., Linnerth-Petrik, N.M., Yu, D.L., Foster, R.A., Menzies, P.I., Diaz-Mendez, A., Chalmers, H.J. and Wootton, S.K. 2013. Experimental transmission of enzootic nasal adenocarcinoma in sheep. Vet. Res. 44, 66. doi: 10.1186/1297-971644-66.

Wilson, D.W. 2016. Tumors of the Respiratory Tract. In: Meuten, D.J. (ed), Tumors in Domestic Animals. John Wiley \& Sons, Inc, Hoboken, NJ, USA. 